\title{
ReViewArticle \\ Effect of drought and saline stress on seed quality
}

\author{
M. PRAKASH
}

\section{SUMMARY}

Seed germination and seedling establishment are the critical stages for all the plants. Insufficient seed germination and seedling emergence under abiotic stress conditions are the main constraints in the production of crops. These abiotic stresses particularly during seedling, vegetative and reproductive stages will certainly affect the crops and drastically reduce not only the seed yield but also the quality of seeds. In this review, an attempt has been made to present the available literature on effect of drought and saline stress in important crops.

Key Words : Drought, Salinity, Seed yield, Quality

How to cite this article : Prakash, M. (2017). Effect of drought and saline stress on seed quality. Internat. J. Plant Sci., 12 (2): 314-320, DOI: 10.15740/HAS/IJPS/12.2/314-320.

Article chronicle : Received : 23.02.2017; Accepted : 28.06.2017

M. PRAKASH, Department of Genetics and Plant Breeding, Faculty of Agriculture, Annamalai University, Annamalai Nagar, CHIDAMBRAM (T.N.) INDIA

Email: geeth_prakash@yahoo.co.in 